\title{
Introduction: Justice, Climate Change, and the Distribution of Natural Resources
}

\author{
Fabian Schuppert ${ }^{1}$
}

Published online: 9 December 2015

(c) Springer Science+Business Media Dordrecht 2015

In a world marked by factors as diverse as the over-emitting of greenhouse gases (GHG) and anthropogenic climate change, the mantra of perpetual growth and consumer capitalism, and an ever increasing world population, many natural resources have come under stress and/or increasingly scarce. The result of these trends is in many cases conflict over natural resources and the flows of goods and money stemming from them. Phenomena such as land-grabbing, resource nationalism and the race to the (yet) untapped resources of the deep sea and the Arctic highlight the need for a critical re-assessment of existing and evolving principles of international natural resource governance, as well as for ideas concerning the normative foundation and the distribution of rights to natural resources. At present, millions of people lack access to the most basic and vital natural resources such as clean water, fertile land and a safe environment, while of the roughly 60billion tonnes of raw materials consumed globally each year more than $75 \%$ are consumed by people in the so-called global North, and of the world's annual water consumption $85 \%$ is down to only $12 \%$ of the global population.

In light of these numbers it is hardly surprising that among philosophers and legal and political theorists there is a growing interest in topics such as rights to water and other key resources, and the relationship between resource rights and other rights, such as territorial and property rights. Moreover, the question of who should legitimately hold which resource rights, and whether cultural groups or states should have the right to autonomously decide how to use (or not use) certain resources is hotly debated. Within these debates it is widely acknowledged that we need a solid

Fabian Schuppert

f.schuppert@qub.ac.uk

1 Belfast, UK 
normative framework for devising urgently needed principles for justly and/or equitably sharing access to and use of natural resources.

One of the key questions is the question of ownership: who should own and/or control natural resources? International law has a clear answer to this question, namely, the doctrine of states' permanent sovereignty over natural resources, also called the national resource privilege. The doctrine of permanent sovereignty over natural resources is not without controversy: while some see it as a bastion against (neo-)colonial resource exploitation and a possible gateway to securing more equitable access to and benefitting from resources for the local population within resource-rich states (Wenar 2008), others have criticised the doctrine for being normatively dubious since arguments from state sovereignty, people's attachment to resources, and national improvement of resources all fail to adequately justify the national resource privilege in its current from (Armstrong 2015a; Schuppert 2014). No matter on which of the two sides one stands, the debate over the justifiability of the doctrine of permanent sovereignty highlights a range of important issues and questions: who are the agents or institutions that can claim rights to natural resources? Is it states and their duty to perform certain functions, such as providing for their citizens' needs and generating justice, which grounds claims to control over resources, or is it peoples and their particular values, commitments and ways of living which can base those claims (Miller 2008)? Others would hold that posing the initial question already gets things wrong since the natural resources of the Earth should be seen as something we all own in common (Risse 2012; Vallentyne and Steiner 2000a, b), while another group of theorists argues for a globally equal distribution of natural resource rights based on our shared humanity, or global egalitarian principles, or the idea of individual self-ownership (Casal 2011; Beitz 1979; Barry 1982; Steiner 1999). What is striking is that within the current philosophical debate simple claims that state sovereignty necessarily requires full control over natural resources have lost most of their normative force and appeal, making room for more nuanced claims about the value of a state's or a people's selfdetermination (Moore 2015), or the importance of grounding resource rights in a functionalist reading of statehood.

Another crucial area of debate is to get a better understanding of what resource rights actually are and how they relate to other kinds of rights, such as territorial rights and property rights. Many contributions to the literature treat resource rights as derivatives of territorial rights arguing that the jurisdictional authority that is at the heart of territorial rights extends to or includes control over natural resources (Moore 2012; Nine 2008, 2012; Meisels 2005; Miller 2012). While territorial rights and resource rights are both commonly conceived of as right bundles the exact relationship between these two bundles remains somewhat obscure and contested. Furthermore, we might question whether all natural resources should be treated in the same way or whether the rights to some natural resources such as water or lifesustaining ecosystem services might be distributed independently of claims to jurisdictional authority (Schuppert 2012). Similarly, particular claims of justice might affect how we distribute certain natural resources and how we distribute the benefits and burdens stemming from resources and their consumption (Pogge 2008; Armstrong 2010). Moreover, some resources come with inherent inequalities which 
raises the question of how we should deal for instance with the unequal distribution of rays of sunlight and wind, or the effects of volcanic ash clouds across borders (Mancilla 2015)?

Depending on who we think should control natural resources and depending on the arguments for the position we take, we will also come up with very different responses to the questions of whether past and current resource use is unjust, whether certain agents have duties of global and intergenerational justice to adjust their resource consumption behaviour, and whether compensation is due from some agents to others because of specific resource control, extraction, use and consumption arrangements (Blomfield 2013, 2015; Mazor 2010).

It is amidst these different lines of normative debate that the papers of this special issue seek to carve out key issues and advance the debate.

In her contribution Ayelet Banai presents an original freedom-based account of self-determination, which-in conjunction with a functionalist account of territorial rights-gives rise to a claim to territorial jurisdiction, including jurisdiction over natural resources, for self-determining states and their people. Banai argues, however, that the claim thus developed is a conditional one, since it is only if the principles of reciprocity, universality and equal freedom are fulfilled that states enjoy control over their natural resources. At the same time, the principles of reciprocity, universality and equal freedom also limit the exercise of states' rights to natural resources.

Some resources, however, escape the logic of territorial jurisdiction because of their fluidity, fugacity or simply because they move across borders and jurisdictions. Alejandra Mancilla considers in her essay the case of migratory species and sheds light on the often overlooked injustices in migration caused by the current system with its compartmentalised view of control over resources. Accordingly, Mancilla suggests that a thorough reconceptualization of the current resource governance regime is necessary, allowing for more flexible governance structures so as to deal more justly and more fairly with fluid, fugacious and migratory resources.

Cara Nine also deals with the issue of migration in her article; however, Nine problematizes the normative justifiability of potential state policies to forcefully relocate some citizens because of perceived dangers such as flooding or drought. In so doing, Nine highlights the limitations of states' jurisdictional authority when it comes to issues such as forced relocation and the taking away of people's home. Nine offers an original account of the importance of home, using a functionalist account of space which allows her to carve out the normative significance of attachment to one's home. According to Nine, her arguments could even suggest that a person's right to home is normatively prior to territorial rights, meaning that territorial rights could be ultimately grounded in an account of individual rights to home.

Theresa Scavenius' essay shifts the focus from territorial rights and jurisdiction over natural resources to the issue of climate change and how actual control over (natural and other) resources normatively matters for the ascription of the responsibilities to fight climate change. As Scavenius argues, the widely popular description of resource overconsumption and rising GHG emissions as a tragedy of the commons misconstrues the problem by suggesting that each and every 
individual as a singular rational agent is at fault for causing and failing to effectively combat climate change. Instead-Scavenius suggests-we deal with a tragedy of the few in which a select group of incorporated entities wields inappropriate power over natural resources and in which the institutional set-up and culture causes problems of global proportions. This description of the problem leads Scavenius back to the issue of resource rights and how to secure fair access and benefits for all, stressing the distinction between use rights and the rights of states and corporations to deplete, exploit or pollute.

One way of making the unequal use of resources tangible is to use the conception of an ecological debt that over-consuming or over-emitting agents have incurred through their thriftless ways. Framing the issue as an issue of debt is particularly popular in the context of climate change as a way of capturing the presumably unjust amounts of past and current emissions some countries are responsible for. However, as Megan Blomfield argues in her contribution to this issue the concept of an emissions debt is normatively problematic. As Blomfield shows the argument from historical emissions debts relies on an implicit conception of justice in the distribution of natural resources, in order to be able to advance the claim that the historical use of the climate sink capacity was indeed unjust. According to Blomfield, there is no determinate answer to the question what a fair share of climate sink capacity would have been historically. Therefore, Blomfield suggest that we should broaden our scope and understand overconsumption of the climate sink capacity as a symptom of far-reaching global injustices concerning the control over the world's natural resources.

The idea that past and persisting global injustices should play a significant normative role in distributing the burdens and benefits of carbon sink conservation and avoided deforestation also features in the papers by Ed Page and Fabian Schuppert, both of which take a recent argument by Armstrong (2015b) on the duties involved in the preservation of tropical rainforests as their starting point. Page proposes to use a modified version of the beneficiary-pays-principle (BPP) for distributing the burdens associated with keeping tropical forests intact and avoiding deforestation. Following Page's interpretation of the BPP, developed states incur a duty to finance carbon sink preservation measures in developing countries because of the benefits developed states and their citizens have derived from past emissions which are known to cause global climate change. These benefits are best characterised as a form of unjust enrichment. While developed states thus have to pay, the day-to-day implementation of carbon sink preservation measures is the duty of forested developing states in whose territories the relevant tropical forests are situated.

In his paper Schuppert offers an alternative account of the duties involved in carbon sink preservation. Schuppert rejects BPP-based and fairness-based accounts for a division of labour between developed and developing states, arguing that the primary normative work is done by the legacy of historical injustice and the unequally shared causal responsibility for global climate change. In addition, Schuppert suggests that the ongoing non-compliance of developed states in discharging their duties of global climate justice raises potentially serious normative conflicts for states like Ecuador who have to decide whether they engage in carbon 
sink preservation or whether they pursue alternative policy options, which might benefit domestic adaptation measures and thus increase social climate resilience.

Taken together the seven papers brought together in this special issue touch on a vast array of key normative questions and controversies, breaking new ground in the process. Thus, while the issue of control over natural resources and their distribution is certain to generate a lot more debate over the years to come, this special issue offers a first look at some of the key issues involved. The contributions to this issue push in a range of ways the boundaries and in the process advance the debate by connecting the existing debates on territorial rights, resource rights, just distribution of natural resources, and the ethics of climate change mitigation and adaptation.

Acknowledgments Most of the contributions to this issue proceed from a workshop on 'Sharing Natural Resources in Times of Climate Change: Justice, Culture and Natural Resource Governance' which I organised together with Chris Armstrong as part of the 2014 ECPR Joint Sessions of Workshops in Salamanca. I would like to thank Chris Armstrong for his help in organising the workshop which led to this publication and I also would like to thank the editors of Res Publica Philip Cook and Sune Lægaard for their support as well as the anonymous referee for insightful comments on all the papers.

\section{References}

Armstrong, Chris. 2010. National self-determination, global equality and moral arbitrariness. Journal of Political Philosophy 18: 313-334.

Armstrong, Chris. 2015a. Against 'permanent sovereignty' over natural resources. Politics, Philosophy \& Economics 14: 129-151.

Armstrong, Chris. 2015b. Fairness, free-riding and rainforest protection. Political Theory. doi:10.1177/ 0090591715594840.

Barry, Brian. 1982. Humanity and justice in global perspective. In Nomos XXIV: Ethics, economics and the law, ed. J.R. Pennock and J. Chapman, 219-252. New York: New York University Press.

Beitz, Charles. 1979. Political theory and international relations. Princeton: Princeton University Press.

Blomfield, Megan. 2013. Global common resources and the just distribution of emission shares. Journal of Political Philosophy 21: 283-304.

Blomfield, Megan. 2015. Climate change and the moral significance of historical injustice in natural resource governance. In The ethics of climate governance, ed. Aaron Maltais and Catriona McKinnon, 3-22. Rowman: Littlefield International.

Casal, Paula. 2011. Global taxes on natural resources. Journal of Moral Philosophy 8: 307-327.

Mancilla, Alejandra. 2015. The volcanic asymmetry, or the question of permanent sovereignty over natural disasters. Journal of Political Philosophy 23: 192-212.

Mazor, Joseph. 2010. Liberal justice, future people, and natural resource conservation. Philosophy \& Public Affairs 38: 380-408.

Meisels, Tamar. 2005. Territorial rights. Dordrecht: Springer.

Miller, David. 2008. National responsibility and global justice. Oxford: Oxford University Press.

Miller, David. 2012. Territorial rights: Concept and justification. Political Studies 60: 252-268.

Moore, Margaret. 2012. Natural resources, territorial right, and global distributive justice. Political Theory 40: 84-107.

Moore, Margaret. 2015. A political theory of territory. Oxford: Oxford University Press.

Nine, Cara. 2008. A Lockean theory of territory. Political Studies 56: 148-165.

Nine, Cara. 2012. Global justice and territory. Oxford: Oxford University Press.

Pogge, Thomas. 2008. World poverty and human rights: Cosmopolitan responsibilities and reforms, 2nd ed. Cambridge: Polity.

Risse, Mathias. 2012. On global justice. Princeton: Princeton University Press.

Schuppert, Fabian. 2012. Reconsidering resource rights: The case for a basic right to the benefits of lifesustaining eco-system services. Journal of Global Ethics 8: 215-225. 
Schuppert, Fabian. 2014. Beyond the national resource privilege: Towards an international court of the environment. International Theory 6: 68-97.

Steiner, Hillel. 1999. Just taxation and international redistribution. In Global justice. Nomos XLI, ed. Ian Shapiro, and Lea Brilmayer, 171-191. New York: New York University Press.

Vallentyne, Peter, and Hillel Steiner (eds.). 2000a. The origins of left-libertarianism. Basingstoke: Palgrave.

Vallentyne, Peter, and Hillel Steiner (eds.). 2000b. Left-libertarianism and its critics: The contemporary debate. Basingstoke: Palgrave.

Wenar, Leif. 2008. Property rights and the resource curse. Philosophy \& Public Affairs 36: 2-32. 